which is in any case necessary to make the British system flexible.

As always in British education bills, the big issues will concern the schools. Britain is not the only industrial nation whose secondary education is no longer matched to modern needs, so that some attention to these questions is entirely proper. The British government confirmed last week its sensible plan (see Nature 327, 448; 1987) to institute a nationally applicable curriculum for secondary schools, although it is far from clear what that curriculum will consist of, and whether it will suit the need. But the government seems also determined to muddy the issue by its proposals for weakening the links between schools and local education authorities (which may be desirable) and for encouraging intending secondary-school students to apply for places at schools of their choice (which, on the face of things, belies the purpose of a national curriculum - a degree of uniformity). Both proposals will be contentious. The second, justified by the rubric "parental choice", is inadequately thought through and may yet prove to be what its critics say it is intended to be, a device for allowing educational ghettoes to persist in British public education. The Secretary of State for Education and Science, Mr Kenneth Baker, will have to think quickly to find a means of avoiding this pitfall before the autumn.

\section{Centres for competition}

The US National Science Foundation is embarking on overdue growth - not without risk.

IT is no accident that the US National Science Foundation (NSF) has become the most favoured of the Reagan administration's instruments for research support. Its chief claim on public affection is the diversity of its projects, almost all of which are managed by university researchers (as with simple project grants) or by consortia of universities (running observatories and other central services). Although NSF does from time to time spend substantial sums of money (on telescopes, for example) its bills are always small compared with those of, say, the Department of Energy, traditionally responsible for building particle accelerators, or the National Aeronautics and Space Administration, which has spent $\$ 1,200$ million on the Hubble Space Telescope. Moreover, NSF differs from other agencies spending money on research, such as the National Institutes of Health (NIH), in its ability and even readiness to turn its mind to what appear to be national problems. Now that the United States has taken fright that US industry may no longer be internationally competitive, NSF has manfully stepped forward with an offer to help. No wonder that the administration plans that NSF's budget should be doubled over the next five years. (It should be clear in a few weeks whether Congress will agree to the first tranche of 17 per cent.)

But how can a grant-making organization which must almost passively respond to the requests that others make upon it safely direct a research commmunity's efforts towards industrially, and even commercially, strategic goals? The most important of NSF's new schemes is that for founding a network of centres for strategic research in well-specified areas of endeavour. The idea, very much that of Dr Erich Bloch, NSF's director, is that the centres should be linked geographically and otherwise with universities but that they should be managed separately, and that potential industrial beneficiaries should be involved. Wisely, NSF has taken outside advice before steaming ahead. Whether NSF will be grateful for the less than full-throated endorsement of its plans that has emerged (see p. 5) is another matter.

Caution is nevertheless appropriate. It is still within living memory (in 1970) that NSF, under an earlier management, embarked for similar reasons on its ill-starred programme called "Research Applied to National Needs" (RANN). More recent$l y$, at the beginning of the first Reagan administration, the US
Department of Commerce was flirting with a scheme not very different from that now being canvassed by NSF, but of which very little came. The essence of the difficulty, especially acute in an economy at least structurally as competitive as that of the United States, is that of arranging that people who are not directly engaged as cogs in the competitive machine - academics, NSF officials and even industrialists in their role as public servants - should accurately tell what projects will best ensure the rapid improvement of industrial technology. There is plenty of experience elsewhere, in Britain for example, to show that people asked to pick winners in circumstances like these usually choose well for races already run.

Luckily, for NSF, there are many fields in which well-found research centres could have a rapid and beneficial influence in US industry. The great fuss in recent weeks about superconductivity in ternary oxides with perovskite structure, for example, points to a need for means of working out atomic structures in circumstances very different from those in which classical X-ray diffraction is conventionally applicable - where disorder from one unit cell to the next may be crucial, for example. Exactly the same need arises in connection with one of last year's wonders of solid-state physics, the puzzle of quasicrystalline str ' .ctures with fivefold symmetry - a problem fast running into ihe sand for want of data. But semiconductor surfaces and solid structures designed to merge one lattice smoothly into another ( $\mathrm{GaAs}$ is the favourite) predicate the same need. The advantage of working in such a field is that there is a crying need for basic understanding as well as for the practical techniques that will ultimately benefit industry. The danger, which NSF's advisory panel at the US National Academy of Science might more clearly have spelled out, is that attempts to plug gaps already opened between the United States and Japan are likely to lead nowhere, however appealing they may be to the US Congress.

That is why NSF will need strong nerves in spending its enlarged budget. For much of its 30 years, the agency has been small and relatively inconspicuous, able even to make mistakes without bringing trouble down upon itself. As it grows, the pressure to respond to popular causes will also increase and, with it, the temptation to make mistakes. Much will hang on the plan for science and technology centres now being hatched.

\section{Who goes where?}

\section{Estimates of the loss by emigration of skilled people are not exact.}

THE Royal Society's attempt to tell how rapid is the loss of technically trained people from the United Kingdom, published this week (see page 27), is a good illustration of the difficulty of measuring the effects of the migration, commonly known as the "brain-drain". Exactly similar difficulties have been encountered in earlier and less well-conducted surveys - in Britain in 1968 , for example - and would almost certainly arise in places where the loss of skilled people is at once greater and more serious in its consequences, in India for example. For one thing, the statistics are always out of date (the latest British study stops short with figures for 1985). For another, but more important, there is no way of telling which of those who leave for appointments overseas will never return; accurate counts would be possible only after the passage of a lifespan.

But, whatever the statistics, their implications for public policy are not easily discerned. There is no basis for asking technically trained people out of patriotism to stay at home, especially when most of those who emigrate do so, in the first instance anyway, so as to improve their skills. And, in any case, there is, in the West, no legal basis for restraining them. But this week's study almost certainly underestimates the rate at which able people are now leaving Britain, even if the chief consequence of the recent decline of the research enterprise is probably that fewer able people are being produced. 